\title{
Arte como biografía en Felipe Cossío del Pomar
}

\author{
Pablo Sebastián Lozano \\ Universidad de Piura
}

"Después de todo, la biografía de un artista está en su obra". Esta afirmación fue dicha por nuestro protagonista ya en su madurez como pintor de prestigio en la primera mitad del siglo XX y cuando era un reconocido diletante del arte contemporáneo en varios países latinoamericanos. Pudiera parecer una simple constatación de la estrecha relación que existe entre vida y arte. Es cierto, toda creación humana se nutre de la experiencia en una existencia personal irrepetible, ineludible e inescrutable. Pero también a la inversa: esa existencia es a la vez fruto de un esfuerzo mantenido por hacer de la propia vida un logro que trascienda su finitud y en la que cada una de sus realizaciones sea la materialización de ese afán. No es motivo de la presente ponencia indagar de forma exhaustiva en dichos vínculos, quizá porque esta discusión nos llevaría muy lejos. El enunciado con el que he comenzado sirve para poner de relieve que en Felipe Cossío esa reflexión es profunda e inspiradora. Voy a tratar de delimitar en qué términos y según qué contexto esta se concreta, y analizar a su vez el pensamiento que hay detrás de ella.

La afición a descubrir y a sondear en las personas fue una constante durante toda su vida. Ya fuera con la pluma o el pincel siempre le supuso un reto compendiar la personalidad de todo aquel que se cruzara en su camino. Se podría decir que con ese empeño reconocía el papel que jugó cada uno de ellos en la configuración de la sociedad e incluso de su propia individualidad.

Ello se pone de manifiesto en el gusto que tuvo por los retratos, pues era para él sin ninguna duda el género pictórico por excelencia. Llegó a destacar como retratista, y como tal recibió encargos de gente distinguida que acabaron reportándole pingües beneficios. De todas maneras, en los que ponía más empeño era con los que se sentía estrechamente vinculado. En el legado de algunas de sus pinturas que hizo a Piura, su ciudad natal, como germen de un futuro museo de arte destacan los retratos de su esposa Estrella Font y del pintor Emilio Sánchez. ${ }^{1}$ Hay también otros tres que, aunque sin firma, tienen claramente su factura. Se tratarían de un autorretrato, el de su amigo Aníbal

1 Emilio Sánchez (1921-1999) fue un pintor cubano reconocido por sus representaciones de elementos arquitectónicos. 
Ponce y el de un desconocido. Para la Universidad Mayor de San Marcos realizó, en los años cincuenta, retratos de varios de sus rectores, entre los que destacó el de Luis Alberto Sánchez, de quien era muy amigo. Otra persona con la que estuvo muy unido y con la que compartió militancia política fue Víctor Raúl Haya de la Torre, a quien también retrató. Pareciera que la cercanía y la familiaridad tuvieran que estar refrendadas por la respectiva pintura. La complacencia tanto por el retrato como por el autorretrato también se puede constatar por la cantidad que de ellos encontramos en sus libros.

Valga el siguiente fragmento de unas memorias inéditas para abordar cómo entendía este género pictórico. En él describe al famoso torero Juan Belmonte:

De cuerpo menudo, trajeado pulcramente, cabeza grande, rostro oliváceo de enorme mentón, nariz prominente, como las narices rotas de los boxeadores, Juan Belmonte era considerado un hombre feo. Por mi parte dejando de lado mi personal afecto-, siempre le consideré como un tipo de excepcional belleza, por estar dotado de esa fealdad que ha nutrido al arte en sus mejores épocas. Una belleza que algunos reconocían cuando estaba en el ruedo, ante la sangre y la muerte, y que yo percibía en el gesto de su boca rasgada, en aquellos hombros estrechos, en toda la desproporción de rostro y cuerpo unida a esa rara armonía de la forma humana que los artistas calificamos de "desdibujada". Además, la profunda tristeza de su mirada, sus ojos negrísimos preñados de ternura inconmensurable, la síntesis feliz del hombre del pueblo -en lo que este representa de cualidades primigenias- $\mathrm{y}$ aristócrata, en su significación de hombre superior. [...]

¿Por qué si estaba tan "hecho", ningún pintor logró reproducir a Juan con la profundidad de su dimensión humana? ¿Por qué Zuloaga no consiguió la obra maestra que se propuso en los tres retratos, grandes de tamaño, que hizo del torero? Creo que una de las razones de su fracaso fue su empeño en retratar al torero y no a Juan Belmonte. Pintó a un torero en "pose" y se le escapó su personalidad dramática.

Por eso cuando Cossío lo retrata rehúye todo aparato y lo representa lejos de los años de gloria, "sin traje de luces, apagado el brillo de sus ojos, mortalmente herido de nostalgia".

En ese ánimo de captar la personalidad dramática del retratado coincide Cossío con su alter ego, el pintor posimpresionista Paul Gauguin. Lo que ambos pintan "es precisamente su espíritu y más particularmente una representación simbólica de su destino". Y al igual que él, será más conservador en el plano formal que los artistas de vanguardia, en los que "la figura humana no es más que el soporte para una especulación plástica". ${ }^{2}$

2 Pierre Francastel expresa estas palabras para definir que en la vanguardia "la finalidad real de la obra realizada es la de interesarnos por la figura del modelo por sí mismo". Galienne y Pierre Francastel, El retrato. Madrid, Cátedra, 1978, p. 228. 
Es por consiguiente la voluntad de recoger la autenticidad del modelo, desnudo de cualquier otro ropaje que disfrace y lo distraiga de esa pretensión sincera, lo que guía la mano del pintor. Curiosamente su vocación por la historia no lo incitó a recrear el rostro de personajes históricos que fueron objeto de su estudio y fascinación, como si estuviera persuadido de que el ejercicio de la pintura se da en tiempo presente. Cabe como excepción a esta regla el excelente retrato que hizo de Miguel Grau, obsequio a su ciudad natal y que hasta hoy preside la sala de sesiones del concejo municipal.

A la par que ese interés inusitado por el género pictórico del retrato, en Cossío del Pomar está también muy marcada su vocación literaria por las biografías. En casi la mitad de todos sus escritos reivindica, no solo como fuente de inspiración sino también como tema de investigación, la vida de insignes personalidades en la historia del pensamiento y del arte. Un rasgo común a todos sus biografiados es esa voluntad, de la que él también se siente partícipe, de buscar nuevos caminos y atisbar amplios horizontes.

Es Víctor Raúl Haya de la Torre la personalidad sobre la que publica más libros, al constituirse Felipe en su biógrafo oficial, a solicitud del propio Haya. A Paul Gauguin, pintor indómito y genial, le dedica dos libros que, como con Víctor Raúl, serían vueltos a publicar por distintas editoriales y en países diversos. ${ }^{3}$ Señalar que fue el primero en escribir una biografía de este genio en castellano. Pietro Aretino es el último personaje sobre el que escribirá un libro. La predilección por el Divino viene por su prestigio como escritor, erudito y crítico del Renacimiento. Nuevamente escribe a partir de su interés por una vida en la que lo amoral y licencioso convive con el talento y la audacia de fustigar la malicia y la iniquidad.

Su preferencia por la biografía también lo llevó a frecuentar notas breves, con su apreciación personal sobre personajes que regaban muchos de sus escritos. Destaca en este sentido el libro Con los buscadores del camino (Madrid, Editorial Ulises, 1931), en el que ofrece un abanico de semblanzas de personalidades del mundo del arte y de la literatura, a las que tuvo ocasión de conocer personalmente y de las que hizo alguna reseña para la revista Variedades, acompañadas -es importante señalarlo- con el retrato esbozado a carboncillo de los entrevistados. Rasgo común a todos es el ser hombres de una extraordinaria ética y estética vital que con su actuar han ido alumbrando nuevos caminos en un arduo siglo $\mathrm{XX}$, y hacia los cuales no oculta su admiración.

Para acabar con los escritos sobre vidas reseña su Cossío del Pomar en San Miguel de Allende, libro autobiográfico que narra sus vivencias en ese rincón donde pasó los mejores años de su vida. Esta tierra mexicana lo vio emprender su más denodada empresa, y la que más honda huella dejó en su vida: la creación de una Escuela de Bellas Artes. Es muy interesante no solo por sus

Felipe Cossío del Pomar, Arte y vida de Paul Gauguin (Escuela Sintetista). Madrid, Librería Española, 1930; La vida de Pablo Gauguin. Buenos Aires, Schapire 1945. 
tintes autobiográficos, sino también por la galería que brinda de intelectuales, artistas y literatos que encontraron acogida en su casa y en su corazón. Parece ser el punto de partida de unas memorias que, empezando por el periodo más reseñable, no pudo culminar.

La relación entre arte y vida, en la que la verdad estaría necesariamente vinculada al acontecer tanto de la sociedad como del individuo, llevó a Cossío a interesarse tanto por la sociología como por la biografía, y a entroncar ambas disciplinas en la consideración especial de la figura del líder o guía a la que estaba llamado el artista. Así, siguiendo a Hugo Vallenas:

Esta apreciación tan exigente de la responsabilidad social del artista [...] tenía su raíz intelectual en las ideas sobre los hombres y la historia defendidas por el historiador escocés Thomas Carlyle en diversas obras, sobre todo en su libro Los héroes (1841). ${ }^{4}$

Al proponer modelos, no tiene el inconveniente de mostrar a sus biografiados con sus defectos y virtudes, e incluso se decanta por aquellos hombres de caracteres contrastados, con miserias y debilidades pero que se enfrentaron a un medio hostil en pos de un ideal y que acabaron por abrir nuevos horizontes. Ejemplo de esa entraña obstinada fueron todos sus biografiados, desde Paul Gauguin, pasando por Pietro Aretino, hasta llegar a Haya de la Torre, cada uno de los cuales ejemplificó una faceta de la propia vida de Felipe: como pintor, como crítico y como político.

Entender la literatura y el arte como un medio de conocer al hombre le vino a partir de la lectura de Aspects de la biographie (1928), de André Maurois. Hay varios indicios que nos hacen pensar en esa dirección. En primer lugar, que Felipe Cossío se decidiera a escribir su primera biografía: Arte y vida de Paul Gauguin en 1930, dos años después de que lo hiciera el libro de Maurois, apostando por aplicar la premisa de este sobre que toda biografía es una obra de arte, la cual llegaría a su acabada formulación cuando sea un artista quien da su punto de vista sobre otro artista. $Y$ en segundo lugar que la única traducción al castellano de la obra francesa fuera hecha en 1935 por ediciones Ercilla (Santiago de Chile), cuando Luis Alberto Sánchez dirigía esa editorial, siendo muy probable que lo hiciera por sugerencia de su amigo Felipe. Pues bien, según el escritor francés, el problema que presenta la biografía es la contradicción entre el cuidado por la verdad y el deseo de la belleza. Es decir, por un lado, está la investigación de la verdad histórica, que es obra de sabios y que hace de la biografía una ciencia; pero, por otro, la búsqueda de la expresión de una personalidad, que es más bien obra de artistas.

4 Hugo Vallenas, "Prólogos", en L. Alva Castro (ed.), El aprismo es un acierto y una profecía. Cartas de Víctor Raúl Haya de la Torre a Felipe Cossío del Pomar 1948-1975. Lima, Instituto Víctor Raúl Haya de la Torre, 2010, pp. XXXIX-LI. Cito p. XLI. 
Pintura y literatura se unen en un mismo propósito: indagar en la autenticidad de la figura de carne y hueso que se propone como ejemplo a seguir por su integridad moral y su dimensión social.

Tener una experiencia real, vivida, de la persona a retratar se constituye en condición indispensable para la pintura, como si en el trazo del pincel se retuviera la impronta de toda una trayectoria vital que con la muerte desaparece. Tiene la convicción de que la 'auténtica' verdad -la que no está mediatizada por una versión literaria, siempre sospechosa- se alcanza con el trato directo. Esto explicaría la cuasi obsesión que tuvo por cuidar y extender exquisitamente su círculo de amigos y conocidos, como ostentando una galería de ilustres ejemplos de vidas logradas.

Acabo. La vida entendida como una aventura, como una travesía en el mundo exterior. Pero también el arte entendido como hazaña, como un itinerario hacia un mundo interior. Lo que Felipe pretendió finalmente fue hacer de su vida una obra maestra, por lo que se rodeó y contagió de otros ejemplos logrados, y que su quehacer artístico mostrara la capacidad transformadora del genio creador. 